\title{
Graeco Latin squares with three Restrictions on Randomization
}

\author{
${ }^{1}$ Effanga, Effanga O. ${ }^{2}$ Omini, Abam A. ${ }^{3}$ Okonna, Mfon I. \\ ${ }^{I}$ Department of Statistics, University of Calabar, Nigeria \\ ${ }^{2}$ Department of Mathematics, Federal University Lafia, Nigeria \\ ${ }^{3}$ Department of Mathematics/Statistics, Akwa Ibom State Polytechnic, Ikot Osudua, Nigeria
}

\begin{abstract}
In this paper we present another variation of Latin square design called Graeco 3RR - Latin Square design. This design adds one more restriction on randomization to the existing $3 R R$ - Latin square by superimposing two orthogonal $3 R R$ - Latin squares. The existence of a Graeco 3RR-Latin square is proved and illustrated by considering Latin squares of order 4 and 9. A statistical model for the design is presented, the estimators of parameters in the model are derived and the Analysis of Variance procedure is developed. .
\end{abstract}

Keywords: Latin square, Graeco Latin square, 3RR - Latin Square, Graeco 3RR - Latin square, randomization, experimental error, ANOVA.

\section{Introduction}

The principles of experimental designs are randomization, replication and blocking. Randomization is often employed to remove potential for systematic bias on the part of the researcher and to reduce experimental errors. Blocking is randomization within block of homogeneous experimental units. Blocking is necessary to evenly distribute treatment across large potential sources of variation. Replication is repetition of basic experiment. More replications imply more precise inference. Holf (2009). Researchers like Zia (2000) and Colton (2012) had developed procedures to reduce experimental errors. The reduction in error becomes more pronounce in randomized block designs such as Latin Square designs. The existing Graeco - Latin square reduces the experimental error by adding one more restriction on randomization to Latin square by using Greek letters within $\mathrm{P}^{2}$ cells along with the Latin letters in such a manner that no combination of Greek - Latin letters are repeated Hicks and Turner(1973) and Montgomery (1976).

Other associated designs that reduce experimental error are the Youden square which allows rectangular arrangements, Hicks and Turner (1973); the Cross Over design which is a special case of the Latin square design, Cochran and Cox (1957). In addition, there are systematic squares such as the Knut and Vik which have been used by experimenters, but the experimental error is in question on these designs even if there are no interactions Kempthorne (1952); Fisher (1966) and Yates (1964).

To further reduce the experimental error, Effanga and Offong (2016) extended randomization to three dimensional, not as in Graeco Latin square, but by considering rows, columns and regions. They called their design a "Latin square design with three restrictions on randomization(3RR - Latin square design)". In a " $\mathrm{x}$ p' 3RR - Latin square design P treatments are arranged in a P x P array such that each treatment appears only once in a row, only once in a column and only once in a region. They showed that their design only exists for Composite order $p \geq 3$. A 3RR - Latin square design has advantage over completely randomized design, randomized block design and ordinary Latin square design in the sense that experimental errors are reduced.

This paper add yet another restriction on randomization to the existing $3 R R$ - Latin square design by superimposing two orthogonal 3RR - Latin squares. Of interest in this paper are the following fundamental questions:

(i) Does there exists pairs of orthogonal 3RR - Latin squares?

(ii) What is the resulting design when two orthogonal 3RR - Latin squares are superimposed?

(iii) What is the statistical model for the resulting design?

(iv) How can the parameters in the model be estimated?

(v) How can the ANOVA be performed?

The answers to the above questions are provided in the following sections.

\section{Orthogonal 3RR - Latin Squares}

Two Latin Squares are said to be orthogonal if on superimposing one with capital letters treatments on another with small letters treatments each pair of capital letter treatment and small letter treatment appears only once in the square, Wikipedia (2014). According to Euler's experiment there exist orthogonal pairs of Latin Squares of any order except 2 and 6, Alvan (2014), Bose and Shrikhande (1960). Hence, there exist orthogonal pairs of 3RR-Latin Squares. 
Example 1: The two ' 4 x 4' $3 R R$ - Latin squares below are orthogonal:
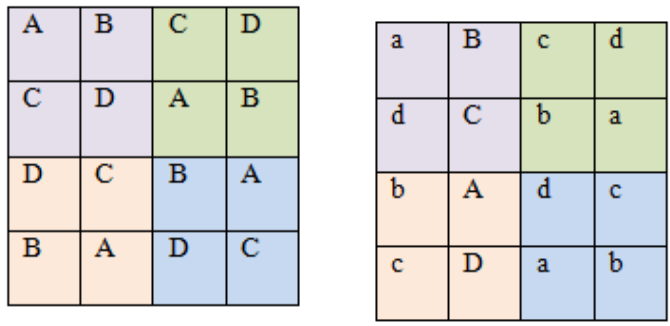

Example 2: The two ' 9 x 9' $3 R R$ - Latin squares below are orthogonal:

\begin{tabular}{|l|l|l|l|l|l|l|l|l|}
\hline A & B & C & D & E & F & G & H & I \\
\hline D & E & F & G & H & I & A & B & C \\
\hline G & H & I & A & B & C & D & E & F \\
\hline C & A & B & F & D & E & I & G & H \\
\hline F & D & E & I & G & H & C & A & B \\
\hline I & G & H & C & A & B & F & D & E \\
\hline B & C & A & E & F & D & H & I & G \\
\hline E & F & D & H & I & G & B & C & A \\
\hline H & I & G & B & C & A & E & F & D \\
\hline
\end{tabular}

\begin{tabular}{|l|l|l|l|l|l|l|l|l|}
\hline a & b & c & d & e & f & g & h & i \\
\hline g & h & i & a & b & c & d & e & f \\
\hline d & e & f & g & h & i & a & b & c \\
\hline e & f & d & b & c & a & h & i & g \\
\hline h & i & g & e & f & d & b & c & a \\
\hline b & c & a & h & i & g & e & f & d \\
\hline f & d & e & c & a & b & i & G & h \\
\hline i & g & h & f & d & e & c & a & b \\
\hline c & a & b & I & g & h & f & d & e \\
\hline
\end{tabular}

Now superimposing the pairs of ' 4 x 4' orthogonal 3RR - Latin squares and ' $9 \times$ 9' orthogonal 3RR - Latin squares we obtain the following ' 4 x 4' and ' 9 x 9' $4 \mathrm{RR}$ - Latin squares, respectively.

' 4 x 4' 4RR - Latin square

\begin{tabular}{|l|l|l|l|}
\hline $\mathrm{Aa}$ & $\mathrm{Bb}$ & $\mathrm{Cc}$ & $\mathrm{Dd}$ \\
\hline $\mathrm{Cd}$ & $\mathrm{Dc}$ & $\mathrm{Ab}$ & $\mathrm{Ba}$ \\
\hline $\mathrm{Db}$ & $\mathrm{Ca}$ & $\mathrm{Bd}$ & $\mathrm{Ac}$ \\
\hline $\mathrm{Bc}$ & $\mathrm{Ad}$ & $\mathrm{Da}$ & $\mathrm{Cb}$ \\
\hline
\end{tabular}

' 9 × 9' 4RR - Latin square

\begin{tabular}{|l|l|l|l|l|l|l|l|l|}
\hline $\mathrm{Aa}$ & $\mathrm{Bb}$ & $\mathrm{Cc}$ & $\mathrm{Dd}$ & $\mathrm{Ee}$ & $\mathrm{Ff}$ & $\mathrm{Gg}$ & $\mathrm{Hh}$ & Ii \\
\hline $\mathrm{Dg}$ & $\mathrm{Eh}$ & $\mathrm{Fi}$ & $\mathrm{Ga}$ & $\mathrm{Hb}$ & $\mathrm{Ic}$ & $\mathrm{Ad}$ & $\mathrm{Be}$ & $\mathrm{Cf}$ \\
\hline $\mathrm{Gd}$ & $\mathrm{He}$ & $\mathrm{If}$ & $\mathrm{Ag}$ & $\mathrm{Bh}$ & $\mathrm{Ci}$ & $\mathrm{Da}$ & $\mathrm{Eb}$ & $\mathrm{Fc}$ \\
\hline $\mathrm{Ce}$ & $\mathrm{Af}$ & $\mathrm{Bd}$ & $\mathrm{Fb}$ & $\mathrm{Dc}$ & $\mathrm{Ea}$ & $\mathrm{Ih}$ & $\mathrm{Gi}$ & $\mathrm{Hg}$ \\
\hline $\mathrm{Fh}$ & $\mathrm{Di}$ & $\mathrm{Eg}$ & $\mathrm{Ie}$ & $\mathrm{Gf}$ & $\mathrm{Hd}$ & $\mathrm{Cb}$ & $\mathrm{Ac}$ & $\mathrm{Ba}$ \\
\hline $\mathrm{Ib}$ & $\mathrm{Gc}$ & $\mathrm{Ha}$ & $\mathrm{Ch}$ & $\mathrm{Ai}$ & $\mathrm{Bg}$ & $\mathrm{Fe}$ & $\mathrm{Df}$ & $\mathrm{Ed}$ \\
\hline $\mathrm{Bf}$ & $\mathrm{Cd}$ & $\mathrm{Ae}$ & $\mathrm{Ec}$ & $\mathrm{Fa}$ & $\mathrm{Db}$ & $\mathrm{Hi}$ & $\mathrm{Ig}$ & $\mathrm{Gh}$ \\
\hline $\mathrm{Ei}$ & $\mathrm{Fg}$ & $\mathrm{Dh}$ & $\mathrm{Hf}$ & $\mathrm{Id}$ & $\mathrm{Ge}$ & $\mathrm{Bc}$ & $\mathrm{Ca}$ & $\mathrm{Ab}$ \\
\hline $\mathrm{Hc}$ & $\mathrm{Ia}$ & $\mathrm{Gb}$ & $\mathrm{Bi}$ & $\mathrm{Cg}$ & $\mathrm{Ah}$ & $\mathrm{Ef}$ & $\mathrm{Fd}$ & $\mathrm{De}$ \\
\hline
\end{tabular}

III. The statistical model for the 4RR - Latin square

A statistical model for the 4RR - Latin square design is given by

$\mathrm{y}_{\mathrm{ijkrs}}=\mu+\alpha_{\mathrm{i}}+\beta_{\mathrm{j}}+\gamma_{\mathrm{k}}+\tau_{\mathrm{r}}+\psi_{\mathrm{s}}+\mathrm{e}_{\mathrm{ijkrs}} ; \mathrm{i}, \mathrm{j}, \mathrm{k}=1,2, \ldots, \mathrm{p}$

Where,

$\mathrm{y}_{\mathrm{ijkrs}}=$ Observation on experimental unit in row $\mathrm{i}$, column $\mathrm{j}$, region $\mathrm{k}$ to which capital letter treatment $\mathrm{r}$ and small letter treatment s are applied

$\alpha_{\mathrm{i}}=$ Row i effect

$\beta_{\mathrm{j}}=$ Column $\mathrm{j}$ effect

$\gamma_{\mathrm{k}}=$ Region $\mathrm{k}$ effect

$\tau_{\mathrm{r}}=$ Capital letter Treatment $\mathrm{r}$ effect 
$\psi_{\mathrm{s}}=$ Small letter Treatment s effect

$\mu=$ Overall mean

$\mathrm{e}_{\mathrm{ijkrs}}=$ Random error term which is assumed to be $\operatorname{NID}\left(0, \sigma^{2}\right)$

\section{Estimation of Parameters}

It is important to note that in a Graeco 3RR - Latin Square there are only $p^{2}$ experimental units to be used in the experiment instead of $\mathrm{p}^{5}$ possible experimental units needed in a complete four way layout. Thus the use of Graeco 3RR - Latin Square design results in the savings in observations by a factor $1 / \mathrm{p}^{3}$ observations over the complete four layouts.

From equation (1), the sum of squares of errors is

$$
\sum_{i=1}^{p} \sum_{j=1}^{p} \sum_{k=1}^{p} \sum_{r=1}^{p} \sum_{s=1}^{p} e_{i j k r s}^{2}=\sum_{i=1}^{p} \sum_{j=1}^{p} \sum_{k=1}^{p} \sum_{r=1 \mathrm{~s}=1}^{p} \sum_{i j k r s}^{p}\left(\mu-\alpha_{\mathrm{i}}-\beta_{\mathrm{j}}-\gamma_{\mathrm{k}}-\tau_{\mathrm{r}}-\psi_{\mathrm{s}}\right)^{2}
$$

Differentiating equation (2) with respect to $\mu, \alpha_{\mathrm{i}}, \beta_{\mathrm{j}}, \Upsilon_{\mathrm{k}}, \tau_{\mathrm{r}}$ and $\psi_{\mathrm{s}}$ respectively, and equating to zero, we obtain the following system of equations:

$$
\begin{aligned}
& \sum_{i=1}^{p} \sum_{j=1}^{p} \sum_{k=1}^{p} \sum_{r=1}^{p} \sum_{\mathrm{s}=1}^{p} y_{i j k r s}-\mathrm{p}^{2} \mu-\mathrm{p} \sum_{\mathrm{i}=1}^{p} \alpha_{\mathrm{i}}-\mathrm{p} \sum_{\mathrm{j}=1}^{p} \beta_{j}-\mathrm{p} \sum_{\mathrm{k}=1}^{p} \gamma_{\mathrm{k}}-\mathrm{p} \sum_{\mathrm{r}=1}^{p} \tau_{\mathrm{r}}-\mathrm{p} \sum_{\mathrm{s}=1}^{p} \psi_{s}=0 \\
& \quad \sum_{j=1}^{p} \sum_{k=1}^{p} \sum_{r=1}^{p} \sum_{\mathrm{s}=1}^{p} y_{i j k r s}-\mathrm{p} \mu-\mathrm{p} \alpha_{\mathrm{i}}-\mathrm{p} \sum_{\mathrm{j}=1}^{p} \beta_{\mathrm{j}}-\mathrm{p} \sum_{\mathrm{k}=1}^{p} \gamma_{\mathrm{k}}-\mathrm{p} \sum_{\mathrm{r}=1}^{p} \tau_{1}-\mathrm{p} \sum_{\mathrm{s}=1}^{p} \psi_{\mathrm{s}}=0 \\
& \quad \sum_{i=1}^{p} \sum_{k=1}^{p} \sum_{r=1 \mathrm{~s}=1}^{p} \sum_{i j k r \mathrm{~s}}^{p} y_{\mathrm{p}} \mu-\mathrm{p} \sum_{\mathrm{i}=1}^{p} \alpha_{\mathrm{i}}-\mathrm{p} \beta_{\mathrm{j}}-\mathrm{p} \sum_{\mathrm{k}=1}^{p} \gamma_{\mathrm{k}}-\mathrm{p} \sum_{\mathrm{r}=1}^{p} \tau_{\mathrm{r}}-\mathrm{p} \sum_{\mathrm{s}=1}^{p} \psi_{\mathrm{s}}=0 \\
& \quad \sum_{i=1}^{p} \sum_{j=1}^{p} \sum_{r=1}^{p} \sum_{\mathrm{s}=1}^{p} y_{i j k r s}-\mathrm{p} \mu-\mathrm{p} \sum_{\mathrm{i}=1}^{p} \alpha_{\mathrm{i}}-\mathrm{p} \sum_{\mathrm{j}=1}^{p} \beta_{\mathrm{j}}-\mathrm{p} \gamma_{\mathrm{k}}-\mathrm{p} \sum_{\mathrm{r}=1}^{p} \tau_{\mathrm{r}}-\mathrm{p} \sum_{\mathrm{s}=1}^{p} \psi_{\mathrm{s}}=0 \\
& \sum_{i=1}^{p} \sum_{j=1}^{p} \sum_{k=1}^{p} \sum_{\mathrm{s}=1}^{p} y_{i j k r s}-\mathrm{p} \mu-\mathrm{p} \sum_{\mathrm{i}=1}^{p} \alpha_{\mathrm{i}}-\mathrm{p} \sum_{\mathrm{j}=1}^{p} \beta_{\mathrm{j}}-\mathrm{p} \sum_{\mathrm{k}=1}^{p} \gamma_{\mathrm{k}}-\mathrm{p} \tau_{\mathrm{r}}-\mathrm{p} \sum_{\mathrm{s}=1}^{p} \psi_{\mathrm{s}}=0
\end{aligned}
$$

Assuming

$$
\sum_{\mathrm{i}=1}^{\mathrm{p}} \alpha_{\mathrm{i}}=\sum_{\mathrm{j}=1}^{\mathrm{p}} \beta_{\mathrm{j}}=\sum_{\mathrm{k}=1}^{\mathrm{p}} \gamma_{\mathrm{k}}=\sum_{\mathrm{r}=1}^{\mathrm{p}} \tau_{\mathrm{r}}-\sum_{\mathrm{s}=1}^{p} \psi_{\mathrm{s}}=0
$$

Equations (3) through (7) reduce to:

$$
\begin{aligned}
& \sum_{i=1}^{p} \sum_{j=1}^{p} \sum_{k=1}^{p} \sum_{r=1 \mathrm{~s}=1}^{p} \sum_{i j k r s}-\mathrm{p}^{2} \mu=0 \\
& \sum_{j=1}^{p} \sum_{k=1}^{p} \sum_{r=1}^{p} \sum_{\mathrm{s}=1}^{p} y_{i j k r s}-\mathrm{p} \mu-\mathrm{p} \alpha_{\mathrm{i}}=0 \\
& \sum_{i=1}^{p} \sum_{k=1}^{p} \sum_{r=1 \mathrm{~s}=1}^{p} \sum_{i j k r s}-\mathrm{p} \mu-\mathrm{p} \beta_{\mathrm{j}}=0 \\
& \sum_{i=1}^{p} \sum_{j=1}^{p} \sum_{r=1}^{p} \sum_{\mathrm{s}=1}^{p} y_{i j k l}-\mathrm{p} \mu-\mathrm{p} \gamma_{\mathrm{k}}=0
\end{aligned}
$$




$$
\begin{aligned}
& \sum_{i=1}^{p} \sum_{j=1}^{p} \sum_{k=1 \mathrm{~s}=1}^{p} \sum_{i j k r s}-\mathrm{p} \mu-\mathrm{p} \tau_{\mathrm{r}}=0 \\
& \sum_{i=1}^{p} \sum_{j=1}^{p} \sum_{k=1}^{p} \sum_{\mathrm{r}=1}^{p} y_{i j k r s}-\mathrm{p} \mu-\mathrm{p} \psi_{\mathrm{s}}=0
\end{aligned}
$$

Solving equations (9) through (14) simultaneously, yields the following estimates of parameters

$$
\begin{aligned}
& \hat{\mu}=\overline{\mathrm{y}} \\
& \alpha_{i}=\overline{\mathrm{y}}_{i \ldots .}-\overline{\mathrm{y}}, 1,2, \ldots, \mathrm{p} \\
& \beta_{j}=\overline{\mathrm{y}}_{. j \ldots}-\overline{\mathrm{y}}, 1,2, \ldots, \mathrm{p}, \\
& \gamma_{k}=\overline{\mathrm{y}}_{. . . . .}-\overline{\mathrm{y}}, 1,2, \ldots, \mathrm{p} \\
& \tau_{r}=\overline{\mathrm{y}}_{. . . r .}-\overline{\mathrm{y}}, 1,2, \ldots, \mathrm{p} \\
& \psi_{s}=\overline{\mathrm{y}}_{. . . . s}-\overline{\mathrm{y}}, 1,2, \ldots, \mathrm{p}
\end{aligned}
$$

\section{The Analysis of Variance}

The Analysis of Variance consist of partitioning the total sum of squares $\left(\mathrm{SST}_{0}\right)$ into its component parts, the sum of squares for row $\left(\mathrm{SSR}_{\mathrm{O}}\right)$, sum of squares for column (SSC), sum of squares for region $\left(\mathrm{SSR}_{\mathrm{e}}\right)$, sum of squares for capital letter treatments (SST), sum of squares for small letter treatments, and sum of squares for error (SSE).

That is,

$$
\mathrm{SST}_{0}=\mathrm{SSR}_{\mathrm{O}}+\mathrm{SSC}+\mathrm{SSR}_{\mathrm{E}}+\mathrm{SST}_{\mathrm{C}}+\mathrm{SST}_{\mathrm{S}}+\mathrm{SSE}
$$

Where

$$
S S T_{0}=\sum_{i=1}^{p} \sum_{j=1}^{p} \sum_{k=1}^{p} \sum_{r=1}^{p} \sum_{\mathrm{s}=1}^{p} y_{i j k r s}^{2}-\mathrm{CF}
$$

with degrees of freedom, $v=p^{2}-1$

$$
\mathrm{SSR}_{\mathrm{O}}=\frac{1}{\mathrm{p}} \sum_{\mathrm{i}=1}^{\mathrm{p}} \mathrm{y}_{\mathrm{i} . . .}^{2}-\mathrm{CF}
$$

with degrees of freedom, $v=p-1$

$$
\mathrm{SSC}=\frac{1}{\mathrm{p}} \sum_{\mathrm{j}=1}^{\mathrm{p}} \mathrm{y}_{\mathrm{j} . . .}^{2}-\mathrm{CF}
$$

with degrees of freedom, $v=p-1$

$$
\mathrm{SSR}_{\mathrm{E}}=\frac{1}{\mathrm{p}} \sum_{\mathrm{k}=1}^{\mathrm{p}} \mathrm{y}_{\text {..k. }}^{2}-\mathrm{CF}
$$

with degrees of freedom, $v=p-1$

$$
\begin{aligned}
& S S T_{C}=\frac{1}{\mathrm{p}} \sum_{i=1}^{p} y_{\ldots . .}^{2}-\mathrm{CF} \\
& S S T_{S}=\frac{1}{\mathrm{p}} \sum_{i=1}^{p} y_{\ldots . . S}^{2}-\mathrm{CF}
\end{aligned}
$$

with degrees of freedom, $v=p-1$

$$
\mathrm{SSE}=\mathrm{SST}_{0}-\mathrm{SSR}_{0}-\mathrm{SSC}-\mathrm{SSR}_{\mathrm{E}}-\mathrm{SST}
$$

with degrees of freedom, $v=(p-1)(p-3)$ 


$$
\mathrm{CF}=\left(\frac{\sum_{\mathrm{i}=1}^{\mathrm{p}} \sum_{\mathrm{j}=1}^{\mathrm{p}} \sum_{\mathrm{k}=1}^{\mathrm{p}} \sum_{r=1 \mathrm{~s}=1}^{p} \sum_{i j k r s}^{\mathrm{p}} y_{i}}{\mathrm{p}}\right)^{2}
$$

is a correction factor.

Following the general principle, it is easy to construct the ANOVA table for our design to enable us test the following hypotheses

$$
\begin{aligned}
& \mathrm{H}_{\mathrm{o}}: \alpha_{\mathrm{i}}=0, \text { for all } \mathrm{i} \\
& \mathrm{H}_{\mathrm{o}}: \beta_{\mathrm{j}}=0, \text { for all } \mathrm{j} \\
& \mathrm{H}_{\mathrm{o}}: \gamma_{\mathrm{k}}=0, \text { for all } \mathrm{k} \\
& \mathrm{H}_{\mathrm{o}}: \tau_{\mathrm{r}}=0, \text { for all } \mathrm{r} \\
& \mathrm{H}_{\mathrm{o}}: \psi_{\mathrm{s}}=0, \text { for all } \mathrm{s}
\end{aligned}
$$

The ANOVA table is shown below

\begin{tabular}{|l|l|l|l|l|}
\hline Source of variation & Degree of freedom & Sum of Squares & Mean Square & F-ratio \\
\hline Row & $\mathrm{P}-1$ & $\mathrm{SSR}_{0}$ & $\mathrm{MSR}_{0}$ & $\mathrm{~F}_{\mathrm{RO}}$ \\
\hline Column & $\mathrm{P}-1$ & $\mathrm{SSC}_{\mathrm{N}}$ & $\mathrm{MSC}$ & $\mathrm{F}_{\mathrm{C}}$ \\
\hline Region & $\mathrm{P}-1$ & $\mathrm{SSR}_{\mathrm{E}}$ & $\mathrm{MSR}_{\mathrm{E}}$ & $\mathrm{F}_{\mathrm{RE}}$ \\
\hline Capital letter Treatment & $\mathrm{P}-1$ & $\mathrm{SST}_{\mathrm{C}}$ & $\mathrm{MST}_{\mathrm{C}}$ & $\mathrm{F}_{\mathrm{CT}}$ \\
\hline Small letter Treatment & $\mathrm{P}-1$ & $\mathrm{SST}_{\mathrm{S}}$ & $\mathrm{MST}_{\mathrm{S}}$ & $\mathrm{F}_{\mathrm{ST}}$ \\
\hline Error & $(\mathrm{P}-1)(\mathrm{p}-4)$ & $\mathrm{SSE}_{\mathrm{N}}$ & $\mathrm{MSE}$ & \\
\hline Total & $\mathrm{P}^{2}-1$ & $\mathrm{SST}_{0}$ & & \\
\hline
\end{tabular}

In the above ANOVA table, the Mean squares and the F - ratios are obtained as follows

$$
\begin{aligned}
& \mathrm{MSR}_{\mathrm{O}}=\frac{\mathrm{SSR}_{\mathrm{o}}}{\mathrm{P}-1} \\
& \mathrm{MSC}=\frac{\mathrm{SSC}}{\mathrm{P}-1} \\
& \mathrm{MSR}_{\mathrm{E}}=\frac{\mathrm{SSR}_{\mathrm{E}}}{\mathrm{P}-1} \\
& \mathrm{MST}_{\mathrm{C}}=\frac{\mathrm{SST}_{\mathrm{C}}}{\mathrm{P}-1} \\
& \mathrm{MST}_{\mathrm{S}}=\frac{\mathrm{SST}_{\mathrm{S}}}{\mathrm{P}-1} \\
& \mathrm{MSE}=\frac{\mathrm{SSE}}{(\mathrm{P}-1)(\mathrm{P}-4)} \\
& \mathrm{F}_{\mathrm{Ro}}=\frac{\mathrm{MSR}_{0}}{\mathrm{MSE}_{\mathrm{C}}} \\
& \mathrm{F}_{\mathrm{C}}=\frac{\mathrm{MSC}_{\mathrm{MSE}}}{\mathrm{F}_{\mathrm{RE}}=\frac{\mathrm{MSR}_{\mathrm{E}}}{\mathrm{MSE}_{\mathrm{CT}}}} \\
& \mathrm{F}_{\mathrm{ST}}=\frac{\mathrm{MST}_{\mathrm{C}}}{\mathrm{MSE}} \\
& \mathrm{FSE}_{\mathrm{S}}
\end{aligned}
$$


$H_{o}$ is rejected at $\alpha \%$ level of significance if the calculated $F$ - ratios are greater than $F_{\alpha}$ with $(p-1)$ numerator degree of freedom and $(p-1)(p-4)$ denominator degree of freedom.

Lemma: Stevens (2011)

The number of squares in a set of mutually orthogonal Latin squares of sides' $p$ is not greater than $p-1$

Theorem: The number of squares in a set of mutually orthogonal 3RR - Latin squares of sides' $p$ is at most ( $p-$ 2)

Proof: Considering the Analysis of variance, the differences between rows, columns and regions accounts for $(p-1)$ degrees of freedom. Since the total degrees of freedom is $\left(p^{2}-1\right)$ it follows that there are $(p+1)$ methods of subdivision. Of these rows, columns and regions account for 3 , leaving $(\mathrm{p}-2)$ subdivisions by letters.

\section{Summary and Conclusion}

We have shown that orthogonal pairs of 3RR - Latin squares exists and then superimposed one on the other to form another type of Latin square coined Graeco 3RR - Latin square The statistical model for the Graeco 3RR - Latin square is formulated and the parameters in the model estimated. We develop the analysis of variance procedure to test the significance of the parameters in the model. In conclusion, we have proved that there are at most $(p-2)$ squares in the set of mutually orthogonal 3RR - Latin square of sides' $p$.

\section{References}

[1]. Alvan, D. (2014): “STAT 507”. Department of Statistics, Pennsylvania State University; http:/ /onlinecourse .science. psu. edu/sta507/node/34

[2]. Bose, R. C. and Shrikhande, S. S. (1960). Further Results on the Construction of Mutually Orthogonal Latin Squares and the Falsity of Euler's Conjection. Transactions of the American Mathematical Society, vol 12, p. 189 - 203

[3]. Cochran, W. G. and Cox M. (1957). Experimental Design. John Wiley and Sons Ltd, New York.

[4]. Colton, J. A. (2012): “Avoiding Mean Square Error Bias in Designed Experiment" published under MiniTab Inc.

[5]. Effanga, E. O. and Offong, N. E. (2016). International Journal of Innovative research and advanced studies. Vol. 3 Issue 9 , Pp 84 87.

[6]. Fisher, R. A. (1966). The Design of Experiments. $8^{\text {th }}$ Edition. Hafner Publishing Company, New York.

[7]. Hicks, C. R. and Turner K. V. (1973). Fundamental Concepts in the Design of Experiment. Oxford University Press, UK.

[8]. Holf, P. D (2009): STA 502 lecture notes

[9]. Kempthorne, O. (1952). The Design and Analysis of Experiments. Wiley, New York

[10]. Stevens, W. L. (2011). The completely orthogonalized Latin square. Annals of Eugenics, Vol. 9, Issue 1.

[11]. Wikipedia (2014): "Design of Experiment" http://en.m.wikipedia.org/wiki/Design of experiments

[12]. Yates, F. (1937). Design and Analysis of Factorial experiment. Tech. Comm. No. 35, Imperial Bereau of Soil Science, London.

[13]. Zia, A. (2000): "Reducing Error in Informal Sector Survey" Published under Australlia Bureau of Statistics, Australia. 